\title{
The Patentability of Signal-Carrying Media
}

\author{
KEVIN T. MCCUSKER ${ }^{*}$
}

\section{INTRODUCTION}

If you're like most Americans, you probably have a cellphone with you at all times. ${ }^{1}$ Although we may appreciate the technology that goes into a smartphone, we may not appreciate the intellectual property underlying that technology. Indeed, an astounding 250,000 active patents relate to smartphones in some way. ${ }^{2}$ With patent licensing fees of approximately $\$ 120$ for a $\$ 400$ phone $-\$ 70$ of which is for software-related patents - patent licensing for cell phones is a $\$ 180$ billion a year business. ${ }^{3}$ Software-related patents can protect the underlying inventions in different ways, including by patenting a device (such as a cell phone), a storage medium (such as a DVD or flash drive), or a method of using a device to implement the invention. ${ }^{4}$

But holders of software patents are missing out on protection of their software inventions during transmission, such as when end users download software from the Internet. ${ }^{5}$ In In re Nuijten, the Federal Circuit determined that a claim in a patent application directed to "[a] signal" was not patent-eligible subject matter, describing the signal as "transitory." The Federal Circuit held that a signal per $s e$ - as opposed to a device or method for making a signal — was not eligible for patent protection because it did not fall into any of the four statutory categories of invention. ${ }^{7}$ Since Nuijten, the United States Patent and Trademark Office (USPTO) does not allow patents to issue that cover signals in transmission, such

* J.D. Candidate, 2019, Indiana University Robert H. McKinney School of Law; B.S. in Physics, B.S. in Computer Engineering, 2006, University of Notre Dame; M.S. in Physics, 2008, Ph.D. in Physics, 2012, University of Illinois; registered to practice before the United States Patent and Trademark Office.

1. Lee Rainie \& Kathryn Zickuhr, Americans' Views on Mobile Etiquette, PEW RES. CTR. (Aug. 26, 2015), http://www.pewinternet.org/2015/08/26/chapter-1-always-on-connectivity/ [perma.cc/GJ58-QXD2].

2. Mike Masnick, There Are 250,000 Active Patents That Impact Smartphones; Representing One in Six Active Patents Today, TECHDIRT (Oct. 8, 2012), https://www.techdirt.com/ articles/20121017/10480520734/there-are-250000-active-patents-that-impact-smartphonesrepresenting-one-six-active-patents-today.shtml [perma.cc/5VX6-MMVJ].

3. Ann Armstrong et al., The Smartphone Royalty Stack: Surveying Royalty Demands for the Components Within Modern Smartphones (May 29, 2014), available at https://ssrn.com/ abstract=2443848 [perma.cc/VLT2-33V3].

4. Patenting Software, World Intellectual Prop. Org., http://www.wipo.int/sme/en/ documents/software_patents_fulltext.html [https://perma.cc/EM4T-XSCW] (last visited Mar. 29, 2019).

5. In re Nuijten, 500 F.3d 1346, 1351 (Fed. Cir. 2007).

6. Id. at $1351,1353$.

7. Id. at 1357 . 
as software being transmitted over networks, ${ }^{8}$ and the USPTO regularly rejects claims as covering signals per se. ${ }^{9}$ The ability to assert a patent in such a manner may be particularly relevant in the situation where software is imported into the United States, because importation of patent-protected software could only be blocked if the importation infringed on a patent claim. ${ }^{10}$ Several authors of articles have argued that Nuijten was wrongly decided and that signals per se should be patentable. ${ }^{11}$

But, just because a signal per se is not patentable, an inventor is not barred from claiming an invention that covers software in transmission. This Note argues that courts and the USPTO should interpret Nuijten as foreclosing only the patenting of intangible signals, such as pulses of light, and not forbidding the patenting of any transitory invention. Such an interpretation still allows for patent protection of transmission of software by claiming the medium that is carrying the signal, such as an optical fiber. Part I of this Note analyzes the holding of Nuijten, concluding that Nuijten could be read as requiring an article of manufacture to be (i) tangible, (ii) non-transitory, or (iii) both tangible and nontransitory in order to be patentable subject matter. Part II then examines how the courts and the USPTO have interpreted Nuijten. Finally, Part III considers how inventors could patent software in transit, ultimately concluding that a tangible medium carrying a signal — as opposed to the signal itself — is patentable subject matter, regardless of how courts interpret Nuijten.

\section{WHAT IS THE HOLDING OF NUIJTEN?}

\section{A. Procedural Background}

Petrus A.C.M Nuijten, an inventor working for Philips Corporation, ${ }^{12}$ applied for a patent application which disclosed "a technique for reducing distortion induced by the introduction of 'watermarks' into signals," which may be imperceptible to listeners of an audio signal, but may be used by an owner of a copyrighted work to identify that work. ${ }^{13}$ Some of the claims in the application

8. David J. Kappos, Subject Matter Eligibility of Computer Readable Media, 1351 OfF. Gaz. Pat. \& Trademark Office 212 (Feb. 23, 2010), https://www.uspto.gov/web/ offices/com/sol/og/2010/week08/TOC.htm\#ref20 [https://perma.cc/CTM9-V5BD].

9. See, e.g., Ex Parte Krumm, appeal no. $2017-005558$ (P.T.A.B. Jan. 31, 2018).

10. 19 U.S.C. $\S 1337$ (2018).

11. Scott Bloebaum, From Telegraphs to Content Protection: The Evolution of Signals as Patentable Subject Matter Under 35 U.S.C. § 101, 9 N.C. J.L. \& TeCH. 243 (2008); Damien Howard, A Discussion on the Patentability of Signals: Examining In re Nuijten, 8 Nw. J. TECH. \& Intell. Prop. 131 (2009); Dolly Y. Wu \& Steven M. Geiszler, Patentable Subject Matter: What is the Matter with Matter?, 15 VA. J.L. \& TECH. 101 (2010).

12. Brief for Appellant at 2, In re Nuijten, 500 F.3d 1346 (Fed. Cir. 2007) (No. 2006-1371).

13. In re Nuijten, 500 F.3d 1346, 1348 (Fed. Cir. 2007); U.S. Patent Application No. 09/426,519 (filed Oct. 26, 1999). 
were directed to a "signal" encoded using the technique which Nuijten invented. ${ }^{14}$ In his application, Nuijten described his invention as applying to watermarking audio and video signals, such as high-quality audio on a DVD. ${ }^{15}$ The examiner for Nuijten's application rejected the claims ${ }^{16}$ directed to a signal for not being in compliance with 35 U.S.C. $\S 101$, which requires an invention to be a "process, machine, manufacture, or composition of matter." ${ }^{\text {"17 }}$ Nuijten appealed to the Board of Patent Appeals and Interferences, which affirmed the examiner's rejection and held that Nuijten's claim to a signal could be read as claiming a signal in the abstract, without any physical embodiment. ${ }^{18}$ Nuijten then appealed to the Court of Appeals for the Federal Circuit. ${ }^{19}$

\section{B. Examining the Holding in Nuijten}

In its decision, the Federal Circuit first performed claim construction on the disputed claim, disagreeing with the USPTO that the signal could be embodied as "intangible, immaterial strings of abstract numbers" and agreeing with Nuijten's position that the signal, as claimed, requires "some physical carrier of information." ${ }^{20}$ Even though a claim under examination at the USPTO is interpreted under the broadest reasonable interpretation, ${ }^{21}$ the interpretation of the Board was too broad and incorrectly included an abstract string of numbers as being covered by the claim. ${ }^{22}$ However, the Federal Circuit noted that "any tangible means of information carriage will suffice" as an embodiment of the signal. ${ }^{23}$ Nuijten described his signal as being embodied as an audio signal or an encoded audio signal on a DVD. ${ }^{24}$ As a result, the claim covered an audio signal propagating as vibrations through air as well as electrical signals propagating through various media, such as "electrical signals, modulated electromagnetic waves, and pulses in fiber optic cable." 25 For example, Nuijten's signal could be embodied as an electrical signal similar to signals carrying computer data on an Ethernet cable or a Wi-Fi signal. A Wi-Fi signal, like an AM or FM radio signal, encodes information by varying the frequency and amplitude of an

14. In re Nuijten, 500 F.3d at 1348 .

15. U.S. Patent Application No. 09/426,519 (filed Oct. 26, 1999).

16. The claim reads, "[a] signal with embedded supplemental data, the signal being encoded in accordance with a given encoding process and selected samples of the signal representing the supplemental data, and at least one of the samples preceding the selected samples is different from the sample corresponding to the given encoding process." In re Nuijten, 500 F.3d at 1351.

17. Id.

18. Id. at 1352.

19. Id.

20. Id. at 1353 (emphasis in original).

21. In re Zletz, 893 F.2d 319, 321 (Fed. Cir. 1989).

22. In re Nuijten, $500 \mathrm{~F} .3 \mathrm{~d}$ at 1353.

23. Id. (emphasis in original).

24. U.S. Patent Application No. 09/426,519 (filed Oct. 26, 1999).

25. In re Nuijten, 500 F.3d at 1353. 
electromagnetic carrier wave. ${ }^{26}$ For example, receipt of an electromagnetic wave at $2.40 \mathrm{GHz}$ at an antenna on a laptop might signify a digital " 0 ," while a receipt of an electromagnetic wave at $2.39 \mathrm{GHz}$ at the antenna might signify a digital "1." ${ }^{27}$ In this way, an electromagnetic carrier wave can carry digital information or other signals. ${ }^{28}$ An electromagnetic wave, such as light generated by the sun, can travel through a vacuum and does not require a medium such as air or glass to carry the wave. ${ }^{29}$

Having resolved the scope of the claimed signal, the court turned to the question of whether such a signal is patent-eligible. ${ }^{30}$ To be eligible for a patent, a claim must be directed to at least one of the four statutory categories of invention that are present in 35 U.S.C. $\S 101$ : A "process, machine, manufacture, or composition of matter." ${ }^{11}$ The Nuijten majority considered each of the four categories in turn and determined that the claim in question did not fall into any of the four categories. ${ }^{32}$

The Nuijten court had no difficulty dispensing with the possibility that the claimed signal was directed to a process,${ }^{33}$ a machine, ${ }^{34}$ or a composition of matter. ${ }^{35}$ The claimed signal was not directed to a process because a process claim "must cover an act or series of acts," which the claim does not do. ${ }^{36}$ The claimed signal was not directed to a machine because a machine must have a "mechanical device" with "concrete structure," which an electromagnetic wave does not have. ${ }^{37}$ And the claimed signal was not directed to a composition of matter because the definition of a composition of matter is "all compositions of two or more substances and all composite articles, whether they be the results of chemical union, or of mechanical mixture, or whether they be gases, fluids, powders or solids" ${ }^{38}$ and an electromagnetic signal is not any such combination. ${ }^{39}$

However, the Nuijten court gave more attention to the question of whether the claimed signal was an article of manufacture. ${ }^{40}$ The court first examined the text of 35 U.S.C. $\S 101$, which states, "Whoever invents . . any new and useful . . .

26. Inst. Of Electrical AND Electronic Eng'rs, IEEE StANDARD FOr INFORMATion TECHNOLOGY 802.11-2016, at 2277 (2016), available at https://ieeexplore.ieee.org/stamp/ stamp.jsp?tp=\&arnumber $=7786995$.

27. See id.

28. Id.

29. John David Jackson, Classical Electrodynamics 353 (1967).

30. In re Nuijten, $500 \mathrm{~F} .3 \mathrm{~d}$ at 1353.

31. 35 U.S.C. $\$ 101$ (2018).

32. In re Nuijten, $500 \mathrm{~F} .3 \mathrm{~d}$ at 1353.

33. Id. at 1355.

34. Id.

35. Id. at 1357.

36. Id. at 1355.

37. Id.

38. Diamond v. Chakrabarty, 447 U.S. 303, 308 (1980).

39. In re Nuijten, $500 \mathrm{~F} .3 \mathrm{~d}$ at 1357.

40. Id. at 1356. 
manufacture . . may obtain a patent therefor . . .."41 The Supreme Court has defined the verb "manufacture" in the context of $\S 101$ as "the production of articles for use from raw or prepared materials by giving to these materials new forms, qualities, properties, or combinations, whether by hand-labor or by machinery." 42 The noun "manufacture," as used by $\S 101$, "refers to 'articles" resulting from the process of manufacture." particular substance or commodity: as, an article of merchandise; an article of clothing; salt is a necessary article." ${ }^{44}$ In light of those definitions of article and manufacture, the court in Nuijten determined that a manufacture under $\S 101$ must be tangible. ${ }^{45}$ Although an electromagnetic signal "is man-made and physical," the "energy embodying the claimed signal is fleeting and is devoid of any semblance of permanence during transmission." ${ }^{* 46}$ As such, the court found that "[a]ll signals within the scope of the claim do not themselves comprise some tangible article or commodity." ${ }^{, 7}$

An astute reader of this Note might notice an apparent inconsistency in the Nuijten opinion in the use of the word "tangible." When determining the scope of the claim, the court had to determine whether the claims covered "intangible, immaterial strings of abstract numbers," as the USPTO advocated, or the claims were limited to a signal with "physical substance," as Nuijten advocated. ${ }^{48}$ The court sided with Nuijten that the claims did not cover intangible string of abstract numbers but rather only covered "any tangible means of information carriage." In that portion of the opinion, the court appears to use "tangible" to mean physical or not abstract and found that the claimed signal only covered tangible embodiments with a physical information carrier. ${ }^{50}$ However, when discussing the meaning of a "manufacture" as used in $\S 101$, the court found that "manufacture" as used in $\S 101$ referred to "tangible articles or commodities," and a "transient electric or electromagnetic transmission" was not tangible and, therefore, did not fit within that definition. ${ }^{51}$ The court did not address the apparent inconsistent meanings of tangible and the inconsistent determination whether the claimed signal was tangible, although the dissent stated that "the majority conclude[d] that manufactures must be 'tangible." "'52 As used in the remainder of this Note,

41. 35 U.S.C. $\S 101$ (2018).

42. Chakrabarty, 447 U.S. at 308 (quoting Am. Fruit Growers, Inc. v. Brogdex Co., 283 U.S. $1,11(1931))$.

43. In re Nuijten, 500 F.3d at 1356.

44. Id. (quoting 1 Century Dictionary 326 (William Dwight Whitney ed., 1895)) (emphasis in original).

45. Id.

46. Id.

47. Id.

48. Id at 1353 .

49. Id. (emphasis in original).

50. Id.

51. Id. at 1356.

52. Id. at 1359 (Linn, J., dissenting). 
"tangible" refers to something composed of matter and having mass, such as an optical fiber or an electrical cable, and does not include an electromagnetic wave, such as a Wi-Fi signal carrying computer date. Of course, whether any given patent claim is tangible under that definition would be a matter of claim construction, and merely reciting the word "tangible" may not be sufficient to limit the claim to something composed of matter and having mass. In fact, as discussed in more detail below, the USPTO's position is that the broadest reasonable interpretation of a tangible medium includes signals per $\mathrm{se}^{53}$

\section{Possible Interpretations of Nuijten}

Although the court's opinion is clear that the claimed signal was not an article of manufacture, the reason why the claimed signal was not an article of manufacture is not clear. One possible interpretation of the holding is that the court established a rule that an article of manufacture must be tangible. A second possible interpretation of the holding is that the court established a rule that an article of manufacture must be tangible and also cannot be transitory or fleeting.

Considering arguments for the first possible interpretation, the court clearly stated that the signal was not considered patentable because it did not fall into any of the four statutory categories of invention. ${ }^{54}$ The court spent two paragraphs describing why the signal was not an article of manufacture ${ }^{55}$ The first paragraph determined the meaning of a manufacture as used in 35 U.S.C. $\S 101$, and the second paragraph applied the meaning to the claimed signal. ${ }^{56}$ In determining the definition of articles and manufacture, the court did not discuss any temporal requirement, such as a requirement that a manufacture be permanent or stable. ${ }^{57}$ In applying the definition, the court stated, "[ $t]$ hese definitions address 'articles' of 'manufacture' as being tangible articles or commodities. A transient electric or electromagnetic transmission does not fit within that definition." ${ }^{58}$ The court further stated that "any tangibility arguably attributed to a signal is embodied in the principle that it is perceptible" and that "[a]ll signals within the scope of the claim do not themselves comprise some tangible article or commodity," particularly focusing on an embodiment of an electromagnetic carrier wave transmitted through a vacuum. ${ }^{59}$ All of those statements support the interpretation that the court established a rule that an invention must be tangible in order to be an article of manufacture. Therefore, the claimed signal was not an article of

53. Office of Patent Legal Admin., 35 USC $§ 101$ :Statutory Requirements And Four CATEGORIES OF INVENTION 17 (Aug. 2015), available at https://www.uspto.gov/sites/default/ files/101_step1_refresher.pdf [perma.cc/HXH7-ZCYA] ("Not acceptable to just add 'physical' or 'tangible' - Nuijten's ineligible signals were physical and tangible.").

54. In re Nuijten, $500 \mathrm{~F} .3 \mathrm{~d}$ at 1357.

55. Id. at $1356-57$.

56. Id.

57. Id. at 1356.

58. Id.

59. Id. 
manufacture because it was not tangible. In contrast, there is only a single sentence in the two paragraphs that references any temporal aspect of the signal: "In essence, energy embodying the claimed signal is fleeting and is devoid of any semblance of permanence during transmission." ${ }^{\prime 00}$ The court did not make any statement that the fleeting nature of the signal is why the court did not consider the signal to be an article of manufacture, whereas the other statements indicate that an article of manufacture must be tangible.

Considering arguments in favor of the second possible interpretation, the opinion, when read in its entirety, indicates that the court established and applied a rule that an article of manufacture cannot be transitory or fleeting. Although the court only included one sentence related to the fleeting nature of the signal in analyzing whether it is an article of manufacture, other portions of the opinion support the interpretation that the court established a rule that an article of manufacture must be non-transitory by emphasizing the transitory and fleeting nature of some embodiments of the claimed signal. ${ }^{61}$ In the first reference to the holding in the opinion, the court stated that the claim in questions covers "transitory electrical and electromagnetic signals." ${ }^{62}$ The court later stated the holding a second time: "We hold that such transitory embodiments are not directed to statutory subject matter." ${ }^{63}$ The court stated the inquiry required to decide the case as being "whether a transitory, propagating signal is within any of the four statutory categories." ${ }^{4}$ In the conclusion, the court held, "[a] transitory, propagating signal like Nuijten's is not a process, machine, manufacture, or composition of matter." ${ }^{\circ 5}$ In fact, other than the discussion relating to whether the claimed signal is abstract or tangible, the opinion used the word tangible only in the section discussing an article of manufacture, which indicates that the court did not consider tangibility the lone deciding factor. ${ }^{66} \mathrm{In}$ his dissent in Nuijten and his dissent from the denial of the petition for rehearing en banc, Judge Linn indicated that he interpreted the majority opinion in Nuijten as requiring an article of manufacture to be both tangible and non-transitory. ${ }^{67} \mathrm{In}$ particular, Judge Linn wrote that he disagreed with the majority that the Supreme Court's definition of manufacture limits the term to non-transitory, tangible things and disagreed with the majority "that something 'transient' or 'fleeting" cannot constitute a "manufacture." ${ }^{68}$ Although not part of the holding of the court, Judge Linn's explanation of the holding may be persuasive to judges reading and applying Nuijten. One district court judge characterized Nuijten as

60. Id.

61. Id. at 1357.

62. Id. at 1352 (emphasis added).

63. Id. at 1353 (emphasis added).

64. Id. (emphasis added).

65. Id.at 1357 (internal quotes omitted).

66. Id. at $1352-53,1356-57$.

67. Id. at 1358; In re Nuijten, 515 F.3d 1361, 1362 (Fed. Cir. 2007) (Linn, J., dissenting from denial of petition for rehearing en banc).

68. In re Nuijten, 515 F.3d at 1362; In re Nuijten, 500 F.3d at 1358. 
holding that "the signal was not directed at statutory subject matter due to its transitory, fleeting nature." 69

Regardless of any requirements Nuijten may have imposed on the patentability of certain articles of manufacture, Nuijten did not impose any requirements on the patentability of a composition of matter. ${ }^{70}$ The court merely restated the definition of an article of manufacture from Diamond v. Chakrabarty ("all compositions of two or more substances and all composite articles, whether they be the results of chemical union, or of mechanical mixture, or whether they be gases, fluids, powders or solids" ${ }^{\prime 71}$ ) and stated that an electromagnetic wave does not fall into the definition. ${ }^{72}$ In particular, the court did not consider whether a composition of matter had to be non-transitory or tangible. ${ }^{73}$ As Judge Linn pointed out in his dissent in Nuijten, binding precedent ${ }^{74}$ has held that a "transitory, unstable, and non-isolatable" chemical compound is patent-eligible as a composition of matter. ${ }^{75}$

\section{IMPACT AND SUBSEQUENT DEVELOPMENTS OF NUIJTEN}

\section{A. Patenting of Signals}

The most straightforward impact of Nuijten is that signals per se, such as electromagnetic waves, cannot be patented. ${ }^{76}$ Although the scope of signals per $s e$ is not particularly broad, there are inventions that could be embodied as signals that are not eligible for patent protection as a result of Nuijten. ${ }^{77}$ For example, certain exotic states of light have applications in the field of quantum information, including quantum communication, measurement, and computing. ${ }^{78}$ Additionally, certain signals have been patented at the European Patent Office (EPO) ${ }^{79}$ In 1989, the Board of Appeals at the EPO allowed a patent on a "colour

69. Icon Health \& Fitness, Inc. v. Garmin Int'1, 2015 WL 5714248, at *3 (N.D. Utah 2015).

70. In re Nuijten, 500 F.3d at 1357.

71. Diamond v. Chakrabarty, 447 U.S. 303, 308 (1980).

72. In re Nuijten, 500 F.3d at 1357.

73. Id.

74. The Federal Circuit considers the decisions of its predecessor court, the Court of Claims and Patent Appeals, to be binding precedent. See South Corp. v. United States, 690 F.2d 1368, 1369 (Fed. Cir. 1982).

75. In re Nuijten, 500 F.3d at 1359 (Linn, J., dissenting) (quoting In re Breslow, 616 F.2d 516 (C.C.P.A. 1980)).

76. Id. at 1348 .

77. Id.

78. See, e.g., Kevin McCusker \& Paul G. Kwiat, Efficient Optical Quantum State Engineering, 103 Physical ReV. LetTers 16 (2009).

79. Stefan V. Steinbrener \& Bardehle Pagenberg, EPO - TBA Confirms Patentability of an Electrical Signal, EPLAW PATENT BLOG (July 30, 2014), http:/www.eplawpatentblog.com/eplaw/ 2014/07/epo-tba-confirms-patentability-of-an-electrical-signal.html [perma.cc/L7HK-XLE6]. 
television signal." ${ }^{80}$ More recently, the Technical Board of Appeals at the EPO approved a claim directed to "specific modulation of a train of defibrillation pulses separated by pauses." be directed to something "tangible" was "foreign" to European patent law. ${ }^{82}$

\section{B. Effect at the Patent Office}

Prior to Nuijten, software patents often included claims that covered a signal embodied in a carrier wave, such as a signal in an electrical cable or an optical cable. ${ }^{83}$ As a result of Nuijten, the USPTO requires that that any claim directed to computer-readable media (CRM), such as a CD or DVD, be "non-transitory." "4 The USPTO issued guidance in the Official Gazette - the official weekly journal of the USPTO - that the broadest reasonable interpretation (the standard used to determine the scope of a claim at the USPTO $)^{85}$ of a CRM "typically covers forms of non-transitory tangible media and transitory propagating signals per se." ${ }^{96}$ The USPTO has repeatedly affirmed this interpretation in later guidance, explicitly stating that a computer-readable storage medium covers signals and carrier waves. ${ }^{87}$ The guidance states that "transitory embodiments are not directed to statutory subject matter," but it does not provide a definition or explanation for what is transitory. ${ }^{88}$ The PTAB has explicitly rejected the argument that a storage medium does not cover a transitory signal per se in Ex parte Mewherter. ${ }^{89}$ In Mewherter, the PTAB used extrinsic evidence to find that the broadest reasonable definition of a computer-readable storage medium included a carrier wave. ${ }^{90}$ In particular, the PTAB considered published applications assigned to IBM, Hewlett-Packard, Sun, Cisco, Oracle, and Siemens which indicate that the disclosed invention could be embodied as a carrier wave and found that the broadest reasonable interpretation of a storage medium included a carrier wave. ${ }^{11}$

80. Id.

81. Id.

82. Id.

83. See, e.g., Mentor Graphics Corp. v. EVE-USA, Inc., 851 F.3d 1275, 1294 (Fed. Cir. 2017) (a claim was invalid for covering carrier waves); see also Icon Health \& Fitness, Inc. v. Garmin Int'1, 2015 WL 5714248 (N.D. Utah 2015) (a claim was invalid for covering carrier waves).

84. Kappos, supra note 8, at 212.

85. In re Zletz, 893 F.2d 319, 321 (Fed. Cir. 1989).

86. Kappos, supra note 8 , at 212.

87. Office of Patent Legal Admin., Evaluating Subject Matter Eligibility Under 35 USC $\S 101$ : AUgust 2012 UpDATE 14 (Aug. 2012), available at http://www.uspto.gov/patents/ law/exam/101_training_aug2012.pdf [https://perma.cc/JC7U-KTCQ]; OfFICE OF PATENT LEGAL ADMIN., supra note 53, at 17.

88. Kappos, supra note 8, at 212.

89. Ex parte Mewherter, No. 2012-007692, 107 U.S.P.Q.2d (BNA) 1857, 1862 (P.T.A.B. May 8, 2013) (precedential-in-part).

90. Id.

91. Id. at 1860. 
Even using the appellant's definition of "any device or recording medium into which data can be copied and held until some later time, and from which the entire original data can be obtained," the PTAB would find that a signal per se carrying embedded data would qualify as a storage medium because "data can be copied and held by a transitory recording medium, albeit temporarily, for future recovery of the embedded data." ${ }^{\circ 2}$ Mewherter does not provide a definition for transitory media, but only provides examples such as "propagating signals per se," "carrier waves," and "wireless communication links."

The guidance issued in the Official Gazette and decisions such as Mewherter raise two distinct issues. The first and narrower issue is a matter of claim construction. The position of the USPTO is clear that the examiners and the PTAB will read a claim to computer-readable medium as including a carrier wave and signal per se unless the specification or claim makes it clear that such a claim does not cover a signal per se. If a claim is properly construed under the broadest reasonable interpretation standard as covering a signal per se, then rejection under $\S 101$ would be appropriate based on the holding of Nuijten. ${ }^{94}$ Such a rejection is firmly rooted in the clear holding of Nuijten and could not be overcome without a court or Congress overturning Nuijten. ${ }^{95}$

The second and broader issue relates to the question of what rule Nuijten established. As discussed above, Nuijten either established a rule that an article of manufacture must be tangible or a rule that an article of manufacture cannot be transitory (or that an article of manufacture must be both tangible and nontransitory). ${ }^{96}$ If Nuijten only established a rule that an article of manufacture must be tangible regardless of whether it is transitory, then that statement in the USPTO's guidance is simply wrong. Even if Nuijten did establish a rule that articles of manufacture must be non-transitory, Nuijten did not establish any rule that a composition of matter must be non-transitory. ${ }^{97}$ Because a composition of matter can be transitory, ${ }^{98}$ the USPTO's guidance that "transitory embodiments are not directed to statutory subject matter" is, at best, overly broad..$^{99}$

The USPTO's guidance provides that an applicant can overcome a rejection as including transitory embodiments by amending a claim to only cover "nontransitory" embodiments. ${ }^{100}$ Because applicants can overcome such a rejection with a simple amendment that the CRM is non-transitory ${ }^{101}$ and because, historically, most computer software has been distributed through non-transitory

92. Id. at 1862 .

93. Id. at $1859-60$.

94. In re Nuijten, 500 F.3d 1346, 1357 (Fed. Cir. 2007).

95. Id.

96. Id. at $1356-57$.

97. Id. at 1357.

98. Id. at 1359 (Linn, J., dissenting); In re Breslow, 616 F.2d 516, 521 (C.C.P.A. 1980).

99. Kappos, supra note 8, at 212.

100. Id.; Office of Patent Legal Admin., supra note 53, at 17.

101. Office of Patent Legal Admin., supra note 53, at 17. 
media such as a CD or DVD, ${ }^{102}$ applicants have little incentive to proceed with the lengthy and expensive process of an appeal first to the Patent Trial and Appeal Board and, most likely, then to the Federal Circuit. However, as digital distribution of software becomes more common, asserting infringement of a claim embodied as, e.g., a signal in a fiber optic cable becomes more relevant. ${ }^{103}$ Considering if and how software in transmission could be patented requires careful reading of Nuijten and examination of possible alternatives to directly claiming carrier waves. The position of the USPTO is clear that the examiners and the PTAB will read a claim to computer-readable medium as including a carrier wave and signal per se unless the specification or claim makes it clear that such a claim does not cover a signal per se. ${ }^{104}$ While amending a claim to explicitly cover only non-transitory embodiments would be sufficient, that is not the only way that a signal or carrier wave could be excluded. For example, an applicant could define a computer-readable medium in the specification of the patent application as only covering physical medium, such as a CD, DVD, electrical cable, or optical fiber. Additionally, or alternatively, an applicant could state in the claim that the computer-readable medium is composed of matter. Such a limitation would both foreclose the interpretation that the claim covered a signal per se and would also strengthen an argument that the claim was directed to a composition of matter.

\section{Case Law Applying Nuijten}

Since Nuijten, several claims in issued patents have been invalidated as covering a signal per se. ${ }^{105}$ In Mentor Graphics Corp. v. EVE-USA, Inc., the Federal Circuit affirmed the district court's finding that the term "machinereadable medium" in a claim included "carrier waves." "106 Because the "machinereadable medium" included a signal itself, the claim was not patentable. ${ }^{107}$ The Federal Circuit in Mentor Graphics did not shed any light on how the court will interpret Nuijten in the future, because the application of the holding of Nuijten was straightforward once the court construed the claim as covering a signal per se. ${ }^{108}$ In Icon Health \& Fitness, Inc. v. Garmin International, the district court

102. Essential Facts About the Computer and Video Game Industry, Entm't SOFTWARE ASS'N (2015), available at $\mathrm{http} / /$ www.theesa.com/wp-content/uploads/2015/04/ESAEssential-Facts-2015.pdf [perma.cc/GJ58-QXD2] (showing that digital sales of video games exceeded physical sales for the first time in 2014).

103. Id.

104. Ex parte Mewherter, No. 2012-007692, 107 U.S.P.Q.2d (BNA) 1857, 1862 (P.T.A.B. May 8, 2013) (precedential-in-part); Kappos, supra note 8, at 212.

105. Mentor Graphics Corp. v. EVE-USA, Inc., 851 F.3d 1275, 1294 (Fed. Cir. 2017); Icon Health \& Fitness, Inc. v. Garmin Int'1, 2015 WL 5714248, at *5 (N.D. Utah 2015).

106. Mentor Graphics Corp., 851 F.3d at 1294.

107. Id.

108. Id. 
found that a claim directed to a "data signal" 109 was not patentable. ${ }^{110}$ The district court interpreted Nuijten as holding that "the transitory nature of the signal [in Nuijten] precluded it from constituting a manufacture under Section 101."111 The court found that the "lack of permanent form [of the data signal at issue] leads to the conclusion that the data signal does not constitute a tangible article or commodity and therefore does not constitute a manufacture." 112 The district court in Icon Health \& Fitness read Nuijten as requiring some aspect of permanence in an article of manufacture. ${ }^{113}$ In Aatrix Software, Inc. v. Green Shades Software, Inc., the Federal Circuit reversed a district court holding that a claim directed to a "data processing system" was invalid for not having a tangible component, similar to the claim in Nuijten. ${ }^{114}$ The Federal Circuit explained that the claim in Nuijten could not be valid because of a "failure of the claimed matter to come within any of the four statutory categories: process, machine, manufacture, composition of matter," which was not the case for the "data processing system." 115

\section{Importation of Patented Software}

Nuijten also has an impact on the importation of patented software. How and when the digital importation of software can be excluded is not a well-established area of law. Under 35 U.S.C. $\S 271(a)$, a person who imports "any patented invention" into the United States infringes the patent relating to the invention and is liable for infringement to the owner of the patent rights. ${ }^{116} 35$ U.S.C. $§ 271(\mathrm{f})$ further states that a person who exports "all or a substantial portion of the components of a patented invention" may be liable for infringement. ${ }^{117}$ In Eolas Technologies Inc. v. Microsoft Corp., the Federal Circuit affirmed "the district court's holding that 'components,' according to $\S 271(\mathrm{f})(1)$, includes software code on golden master disks." 118

In addition to remedies for acts of infringement established under $\S 271$, patentees have additional remedies to prevent the importation of patented inventions. The International Trade Commission (ITC) has the authority to order an exclusion of importation of any patented "article."119 A recent case at the Federal Circuit reviewing an exclusion order of the ITC, ClearCorrect Operating,

109. U.S. Patent No. 6,626,799 col. $101.10-22$.

110. Icon Health \& Fitness, Inc., 2015 WL 5714248, at *5.

111. Id.

112. $I d$.

113. Id.

114. Aatrix Software, Inc. v. Green Shades Software, Inc., 882 F.3d 1121, 1125 (Fed. Cir. 2018).

115. Id.

116. 35 U.S.C. $\S 271$ (2018).

117. Id. § 271(f).

118. Eolas Technologies Inc. v. Microsoft Corp., 399 F.3d 1325, 1328 (Fed. Cir. 2005).

119. 19 U.S.C. $§ 1337$ (2018). 
LLC, v. International Trade Commission, held that an "article," as used in 19 U.S.C. $§ 1337$, does not include "digital data." ${ }^{20}$ The court based the holding on an interpretation of "articles" as meaning "material things," and concluded that "when there is no importation of 'articles' there can be no unfair act, and there is nothing for the Commission to remedy." ${ }^{21}$ Since the "the only purported 'article' found to have been imported was digital data that was transferred electronically, i.e., not digital data on a physical medium such as a compact disk or thumb drive," there was no underlying importation of an article on which to base an exclusion order. ${ }^{122}$ The court also discussed the difficulty of enforcing an order not to import digital data, noting that "it is difficult to see how one could physically stop electronic transmissions at the borders under the current statutory scheme." 123 The court approvingly quoted the one commissioner of the panel at the ITC who dissented from the exclusion order, who stated that the "exclusion order directed against electronic transmissions could not only have no effect within the context of Section 337-it simply would make no sense as it would not be enforce[able]." 124

The dissent at the Federal Circuit in ClearCorrect did not agree with the majority and would have found that "articles" included software. ${ }^{125}$ In her dissent, Judge Pauline Newman argued that in several similar statutes, "articles" have been interpreted to include software or that software by Internet transmission has been interpreted as an act of importation. ${ }^{126}$ According to Judge Newman, "[t]he Bureau of Customs and Border Protection has established that Internet transmission is 'importation' into the United States." ${ }^{27}$ Judge Newman pointed out that the Court of International Trade acknowledged that "transmissions of software code via the Internet ... a are goods entering into the Customs boundaries of the United States." 128 The Department of Labor has interpreted "software and similar intangible goods" as "articles" for the purpose of the Trade Act. ${ }^{129}$ A law passed shortly before ClearCorrect states that " $[\mathrm{t}]$ he principal negotiating objectives of the United States . . . are . . . to ensure that electronically delivered goods and services receive no less favorable treatment under trade rules and commitments than like products delivered in physical form." 130 While acknowledging that enforcing exclusion orders relating to digital transmissions

120. ClearCorrect Operating, LLC v. Int'l Trade Comm., 810 F.3d 1283, 1286 (Fed. Cir. 2015).

121. Id. at 1290.

122. Id.

123. Id. at 1295 .

124. Id. (quoting In re Certain Digital Models, Inv. No. 337-TA-833, USITC Pub. 4555 (Apr. $3,2014)$ (initiated)).

125. Id. at 1304 (Newman, J., dissenting).

126. Id. at 1309 .

127. Id.

128. Id.

129. Id. at 1310.

130. Id. (citing Pub L. No. 114-26, §§ 102(a)(6), (a)(6)(B)(i), 129 Stat. 320, 325 (2015)). 
may be difficult in some circumstances, Judge Newman argued that "difficulty of enforcing a remedial statute is not grounds for judicial elimination of all remedy." 131

Judge Newman reiterated her opposition to the holding in ClearCorrect in her dissent from the denial of a petition for rehearing en banc. ${ }^{132}$ In addition to the rulings of the Bureau of Customs and Border Protection, the Court of International Trade, the Department of Labor, and a recently-enacted law passed by Congress, Judge Newman cited the Arms Export Control Act (AECA). ${ }^{133}$ The AECA allows the prohibition of "defense article or defense service," which includes by regulations "software . . . directly related to defense articles" and "information in the form of blueprints, drawings, photographs, plans, instructions or documentation." 134 However, ClearCorrect has not been the last word in regard to orders excluding importation of software. After ClearCorrect, the Federal Circuit affirmed an order of the ITC in Cisco Systems, Inc., v. Int'l Trade Comm. barring an infringer of a patented invention from importing components related to the invention, including "related software." 135 The three judge panel in Cisco Systems, which did not have any overlap with the panel in ClearCorrect, did not reference the statements in ClearCorrect that such an order "would make no sense as it would not be enforce[able]."136

The holding in ClearCorrect does not necessarily foreclose the possibility that the ITC could order the exclusion of importation of patented software transmitted digitally. Subsequent holdings, such as Cisco Systems, demonstrate that the ITC can issue valid exclusion orders excluding digital transmission of software. ${ }^{137}$ Although Nuijten is based on an interpretation of article of manufacture under 35 U.S.C. $\S 101$ and ClearCorrect is based on an interpretation of the word articles in 19 U.S.C. $\S 1337$, the holding in ClearCorrect is in consonance with the holding in Nuijten that a signal is not an article. ${ }^{138}$ If software embodied on a transmission medium such as laser pulses on an optical fiber cannot be patented, then such a transmission medium could not infringe on any patent. Although storing or executing the software might be considered a subsequent act of infringement, ClearCorrect suggests that such an act would not be considered an "import" as used in 35 U.S.C. $\S 271$ and that such a subsequent act could be not used as a basis for excluding the transmission of the software under 19 U.S.C. $§ 1337 .{ }^{139}$

The inability to exclude importation of digital transmission of software can

131. Id.

132. ClearCorrect Operating, LLC v. Int'l Trade Comm., 819 F.3d 1334, 1337 (Fed. Cir. 2016) (Newman, J., dissenting from denial of petition for rehearing en banc).

133. Id. at $1340-42$.

134. Id. at 1341 (citing 22 U.S.C. $\S 2753$ (a) and 22 C.F.R. $\S \S 120.10(a)(1)$, (a)(4)).

135. Cisco Sys., Inc. v Int'l Trade Comm., 873 F.3d 1354, 1357 (Fed. Cir. 2017).

136. ClearCorrect, 810 F.3d at 1295.

137. Cisco Sys., 873 F.3d at 1357.

138. ClearCorrect, 810 F.3d at 1286; In re Nuijten, 500 F.3d 1346, 1348 (Fed. Cir. 2007).

139. ClearCorrect, 810 F.3d at 1290. 
be a critical gap in the rights of a patent holder. Consider the scenario of an inventor developing software and obtaining a patent on non-transitory computerreadable media. Such a patent would allow the inventor to exclude the sale or import of fixed media such as CDs or DVDS. If a foreign company developed software that would infringe on the U.S. patent if imported into the United States, the patent owner would be able to exclude such an importation in the form of CDs or DVDs. But that would not prevent the foreign company from selling and digitally transmitting the software directly to end users in the United States. Although the end users would likely be liable for infringement themselves in such situations, suing a large number of end users is difficult, expensive, and timeconsuming, and patent-holders would be better off with the ability to sue the software sellers as well. ${ }^{140}$ A patent owner would have no recourse against the foreign company in such a scenario because there would be no violation or jurisdiction under 35 U.S.C. $\S 271$ and no grounds for an exclusion order under 19 U.S.C. $\S 1337$. If we consider that, as discussed in the introduction of this Note, patent licensing fees for software-related patents for cell phones alone is over $\$ 100$ billion a year, the scale of the problem becomes evident. ${ }^{141}$ Although cell phone manufacturers typically bundle software with the phones and pass the cost of the licensing fees along to the end consumer, a manufacturer could conceivably sell the hardware without corresponding software, with the end user downloading software from outside the United States.

But as this Note argues in Part III, an inventor could perhaps receive a valid patent directed to the transmission medium itself, such as an optical fiber that is carrying software code. The holding of neither Nuijten or ClearCorrect would apply to such a patent because the patent would be directed to an article of manufacture or a composition of matter, not to a signal or to data per se. As a result, ClearCorrect would not foreclose a holder of such a patent from pursuing an exclusion order at the ITC under 19 U.S.C. $\S 1337$. The question before the ITC would be whether transmission of a signal on an optical fiber that transforms the optical fiber from its previous state to one which infringes a patent amounts to "importation ... . of articles that infringe a valid and enforceable United States patent," as recited in $\S 1337 . .^{142}$ On one hand, the ITC could find that the fiber itself is not being imported into the United States, since the fiber

is not moving at all. On the other hand, the ITC could find that, at the point where the fiber intersects with the United States border, the transmitter is transforming the optical fiber to infringe on the claimed invention.

140. See Gaia Bernstein, The Rise Of The End User In Patent Litigation, 55 B.C. L. Rev. 1443 (2014)

141. Armstrong et al., supra note 3, at 2 .

142. 19 U.S.C. $\S 1337$ (B) (2018). 


\section{A TANGIBLE MEDIUM CARRYING TRANSITORY SIGNALS IS PATENTABLE SUBJECT MATTER}

\section{A. Courts and the USPTO Should Interpret Nuijten as Only Requiring That an Article of Manufacture Be Tangible}

As discussed above, courts and the USPTO could interpret Nuijten as either requiring that an article of manufacture be tangible or requiring that an article of manufacture be non-transitory because Nuijten includes statements that support both interpretations. ${ }^{143}$ Courts and the USPTO should interpret Nuijten narrowly as only requiring that an article of manufacture be tangible for four reasons. However, even if Nuijten established a rule that an article of manufacture must be non-transitory, a tangible medium carrying transitory signals would be patentable subject matter.

1. Nuijten Does Not Hold That an Article of Manufacture Must Be Nontransitory.-The court did not clearly state, or even strongly imply, that an article of manufacture must be non-transitory. The court clearly based its decision on whether or not the claimed signal fell into one of the four statutory categories of invention. ${ }^{144}$ However, when defining the scope of an article of manufacture, the court did not discuss temporal aspects at all. When applying the definition of an article of manufacture to the claimed signal, the court only made one mention of the transitory nature of the signal, but did not refer to the transitory nature of the signal when stating the conclusion that the signal was not an article of manufacture. ${ }^{145}$ Although the opinion repeatedly refers to the "transitory, propagating" nature of the claimed signal, those statements are insufficient to establish that the signal is not patentable because it is transitory. ${ }^{146}$

2. Courts and the USPTO Should Interpret Nuijten as Only Imposing a Tangibility Requirement on Articles of Manufacture.-Courts and the USPTO should interpret Nuijten narrowly, as only requiring that an article of manufacture be tangible and not requiring that an article of manufacture be non-transitory. As the dissent in Nuijten pointed out, the Court of Claims and Patent Appeals (the opinions of which are binding precedent on the Federal Circuit ${ }^{147}$ ) held in Breslow that a "transitory, unstable, and non-isolatable" chemical compound could be considered a manufacture. ${ }^{148}$ If a transitory chemical compound can be an article of manufacture, then at least some patentable articles of manufacture are

143. In re Nuijten, $500 \mathrm{~F} .3 \mathrm{~d}$ at $1353,1356$.

144. Id. at $1353,1357$.

145. Id. at 1356 ("In essence, energy embodying the claimed signal is fleeting and is devoid of any semblance of permanence during transmission.”).

146. Id. at $1353,1357$.

147. The Federal Circuit considers the decisions of its predecessor court, the Court of Claims and Patent Appeals, to be binding precedent. See South Corp. v. United States, 690 F.2d 1368, 1369 (Fed. Cir. 1982).

148. In re Nuijten, 500 F.3d at 1359 (Linn, J., dissenting) (quoting In re Breslow, 616 F.2d 516, 519, 522 (C.C.P.A. 1980)). 
patentable. If that is the case, then the court could not establish a rule that articles of manufacture must be non-transitory without overturning prior binding precedent. However, the focus of Breslow was evaluating the invention as a composition of matter, so the statement that the invention could also be considered a manufacture remains, arguably, nonbinding dicta. ${ }^{149}$

3. An Inquiry into Whether an Invention Is Transitory Would Be Both Difficult and Unnecessary. - Courts should not interpret Nuijten as requiring that an article of manufacture be non-transitory because such a requirement would necessitate an inquiry into whether a particular invention is transitory. Nuijten does not provide any guidelines for determining whether an invention is transitory but rather merely asserts that some embodiments of the claimed signal are "transitory," "fleeting," and "devoid of any semblance of permanence."150 Courts, inventors, and examiners at the USPTO would have difficulty determining what qualifies as "non-transitory."

Consider, for example, some possible embodiments of electromagnetic signals. A pulse of light can bounce between two mirrors billions of times before dissipating. ${ }^{151}$ A pulse of light can be slowed down in a cloud of atoms to as slow as eight meters per second or even stopped entirely and stored for macroscopic periods of time. ${ }^{152}$ Radio communications from the Voyager probes sent from outside the solar system take over nineteen hours to reach Earth. ${ }^{153}$ A permanent magnet can create a signal embodied as a permanent magnetic field. ${ }^{154}$

Would those signals be considered transitory? Physicists can store pulses of light in an optical fiber in a loop with continuous amplification and maintain the pulses for hours undisturbed. ${ }^{155}$ The same pulses can be sent and amplified through a long-haul optical fiber to send information. ${ }^{156}$ Would the pulses be considered non-transitory if kept in a closed loop but transitory is sent from one location to another? Considering examples in other fields, it is now common for articles of manufacture to be intentionally designed to lack permanence, such as biodegradable products. ${ }^{157}$ It is conceivable that nanomachines could create

149. Id. at 522 .

150. In re Nuijten, $500 \mathrm{~F} .3 \mathrm{~d}$ at $1353,1356$.

151. Sébastien Gleyzes et al., Quantum Jumps of Light Recording the Birth and Death of a Photon in a Cavity, 446 NATURE 297 (2007).

152. Dmitry Budker et al., Nonlinear Magneto-optics and Reduced Group Velocity of Light in Atomic Vapor with Slow Ground State Relaxation, 83 PhysiCAl ReV. LeTters 1767 (1999); Naomi S. Ginsberg et al., Coherent Control of Optical Information with Matter Wave Dynamics, 445 NATURE 623 (2007).

153. Voyager Mission Status, Jet Propulsion Laboratory: Cal. Inst. of Tech., https://voyager.jpl.nasa.gov/mission/status/ [https://perma.cc/JF8T-N34Q] (last visited Mar. 29, 2019).

154. JACKSON, supra note 29 , at 160.

155. N. H. Seong \& Dug Y. Kim, Experimental Observation of Stable Bound Solitons in a Figure-eight Fiber Laser, 27 OptICS LETTERS 1321 (2002).

156. Id.

157. Ioanna Kyrikou \& Demetris Briassoulis, Biodegradation of Agricultural Plastic Films: 
microscopic articles of manufacture that perform some function and then quickly decay. How long would such manufactures have to exist to be non-transitory? Developing an approach that would allow patent practitioners, patent examiners, and district court judges to answer those questions would be difficult for the Federal Circuit. Such an approach is also unnecessary, because the simple alternative of foregoing such a requirement is available.

4. Intepreting Nuijten to Significantly Narrow Patent-eligible Subject Matter Would Be Against Public Policy.-Construing Nuijten to require that an article of manufacture be non-transitory would be against public policy. Inventions embodied as software patents are no less deserving of patent protection than any other inventions, and inventions embodied in a transmission medium such as an optical cable are no less deserving of patent protection than inventions embodied in a storage medium, such as a DVD or a hard drive. As the Supreme Court noted in Diamond v. Chakrabarty, "Congress intended statutory subject matter to 'include anything under the sun that is made by man." 158 Forbidding patent protection on transitory articles of manufacture would go against the public policy-recognized by Congress and the Supreme Court-to incentivize inventors by offering patent protection on nearly any type of invention. While limiting what inventions are eligible under $\S 101$, the Supreme Court has recognized that implicit exceptions exist for "laws of nature, physical phenomena, and abstract ideas," despite the breadth of the literal language of $\S 101 .{ }^{159}$ The framework the Court applies under $\S 101$ is to first determine whether a particular invention falls into one of the four categories of inventions and then to determine if the invention is directed to one of the judicial exceptions without "significantly more." ${ }^{160}$ Numerous examples of inventions fall into one of the statutory categories of invention that is nonetheless not eligible under $\S 101$ as being directed to a judicial exception, such as a method for hedging risk in commodities trading, ${ }^{161}$ a method for mitigating settlement risk, ${ }^{162}$ or isolated DNA. ${ }^{163}$ However, given the breadth of $\S 101$ to cover "anything under the sun that is made by man," 164 there are few inventions that do not fall within one of the categories of $\S 101$. But intangible information or computer software untethered from some physical embodiment are some examples of inventions that do not fall within $\S 101 .^{165}$ And other examples include claims directed to data or to a

A Critical Review, 15 J. Polymers And EnV'T 125 (2007).

158. Diamond v. Chakrabarty, 447 U.S. 303, 309 (1980).

159. Id.

160. Alice Corp. Pty. Ltd. v. CLS Bank Int'1, 134 S. Ct. 2347, 2353 (2014); Bilski v. Kappos, 561 U.S. 593, 621 (2010).

161. Bilski, 561 U.S. at 611.

162. Alice, 134 S. Ct. at 2353.

163. Ass'n for Molecular Pathology v. Myriad Genetics, Inc., 569 U.S. 576 (2013).

164. Chakrabarty, 447 U.S. at 309.

165. See Microsoft Corp. v. AT\&T, 550 U.S. 437, 449 (2007) ("Abstract software code is an idea without physical embodiment . ...”); M.P.E.P. $§ 2106.03$ (2018). 
number place puzzle. ${ }^{166}$ In each of those cases, the claims were found to be ineligible for patent protection under $\S 101 .{ }^{167}$ In fact, the carrier wave described in Niujten may stand alone as an invention that has a physical embodiment (i.e., an electromagnetic wave) that does not fall into one of the categories of invention. If courts interpret Nuijten as requiring that all articles of manufacture must be non-transitory, then patent-eligible subject matter will be unnecessarily narrowed. In contrast, if courts interpret Nuijten as forbidding patenting of a medium carrying a signal, patent owners may be precluded from preventing the importation of their inventions from overseas. It would be against public policy to interpret patent law to provide a loophole for infringers by allowing the importing of software as signals up until it gets to end users.

\section{B. A Tangible Medium Carrying a Signal Is an Article of Manufacture}

Despite Nuijten's ban on patenting signals per se, an applicant seeking a patent on a signal in transmission may still be able to prevail by claiming the tangible medium carrying the signal, regardless of whether Nuijten is interpreted as requiring an article of manufacture to be non-transitory. Consider the case of an optical fiber carrying pulses of light that correspond to an invention embodied as software. If Nuijten only requires an article of manufacture be tangible, a tangible medium carrying a computer program embodied as an electrical signal should be considered patentable subject matter as an article of manufacture, just as a medium storing a computer program is patentable as an article of manufacture. It is well-established that a non-transitory CRM, such as a CD or DVD, is patentable subject matter because it can be used to transform a preexisting computer into a new machine that performs a task in a new and nonobvious way. ${ }^{168}$ Similarly, a transmission medium such as an optical fiber carrying a computer program as a signal can be used to cause a computer to perform a task in a new and non-obvious way. The optical fiber itself is, of course, a tangible article of manufacture because optical fiber is manufactured and sold as a commodity. But without any additional properties of the signal the

166. Digitech Image Techs., LLC v. Elecs. for Imaging, Inc., 758 F.3d 1344, 1347 (Fed. Cir. 2014); Ex parte Tackett, No. 2013-001376, 2015 WL 5317325 (P.T.A.B. Aug. 31, 2015).

167. Digitech, 758 F.3d at 1347; Ex parte Tackett, 2015 WL 5317325.

168. Digitech, 758 F.3d at 1349; In re Beauregard, 53 F.3d 1583, 1584 (Fed. Cir. 1995) (remanding an appeal back to the USPTO after the Commissioner of Patents conceded that "computer programs embodied in a tangible medium, such as floppy diskettes, are patentable subject matter under 35 U.S.C. $\S 101$ and must be examined under 35 U.S.C. $\S 102$ and 103”); In re Alappat, 33 F.3d 1526, 1545 (Fed. Cir. 1994) (holding that a general-purpose computer programmed to perform rasterizing is patentable "because a general purpose computer in effect becomes a special purpose computer once it is programmed to perform particular functions pursuant to instructions from program software."); In re Lowry, 32 F.3d 1579, 1583 (Fed. Cir. 1994) (holding that a computer configured with a certain type of data structure is patentable subject matter and rejecting application of the printed matter doctrine to computer programs stored in computers.). 
optical fiber is carrying, the fiber would not meet the novelty requirement of 35 U.S.C. $\S 102$ and the non-obvious requirement of 35 U.S.C. $\S 103$. However, a fiber optic cable does not merely passively exist contemporaneously with the signal it carries; rather, the fiber optic cable itself changes as the signal passes through it. ${ }^{169}$ The pulses of light change the physical configuration of the optical fiber. ${ }^{170}$ In particular, the electric field from the electromagnetic wave applies a force to the electrons of the atoms, moving the electrons of the atoms relative to the nuclei of the atoms. ${ }^{171}$ At any given time, the amount of energy from the light pulses stored in the displacement of the electrons is approximately one-third of the overall energy of the signal. ${ }^{172}$ If the external signal could be instantaneously removed, leaving only the displacement of the electrons, the displaced electrons would recreate the light pulse. ${ }^{173}$ In other words, the signal is imprinted on the physical configuration of the optical fiber such that the optical fiber is transformed in a way that can be used to cause a computer receiving the signal to perform a task in a new and non-obvious way. The change in the optical fiber transforms it in a similar way as writing information on a DVD. A claim directed to such an optical fiber does not need to claim the underlying electromagnetic wave per se but need only claim the physical, tangible medium of the optical fiber itself. Such an optical fiber would qualify as patentable subject matter as a tangible article of manufacture and could qualify as being novel and non-obvious based on the properties of the computer program being carried on the fiber.

\section{A Tangible Medium Carrying a Signal Is a Composition of Matter}

Even if courts interpret Nuijten as requiring an article of manufacture to be both tangible and non-transitory, the courts should still consider a tangible medium carrying a signal to be patentable subject matter. Although such a medium would likely be considered transitory and would not qualify as an article of manufacture under that interpretation of Nuijten, the same medium could still qualify as a composition of matter. A composition of matter has been one of the four statutory categories of invention since the Patent Act of 1793. ${ }^{174}$ Except for one minor change, ${ }^{175}$ the four categories have remained unchanged since $1793 .{ }^{176}$

"Congress intended statutory subject matter to include anything under the sun that is made by man." ${ }^{177}$ As noted above, the court in Nuijten referred to the definition of a composition of matter in Chakrabarty, i.e., "all compositions of

169. JACKSON, supra note 29 , at 108.

170. Id.

171. Id.

172. Id.

173. Id.

174. Patent Act of $1793 \S 1,1$ Stat. 318, 319 (1793).

175. Patent Act of 1952, 66 Stat. 792,797 (1952) (adding a "process" as a category of invention as replacement for "art").

176. 35 U.S.C. $\S 101$ (2018); Patent Act of $1793 \S 1,1$ Stat. 318, 319.

177. Diamond v. Chakrabarty, 447 U.S. 303, 309 (1980). 
two or more substances and all composite articles, whether they be the results of chemical union, or of mechanical mixture, or whether they be gases, fluids, powders or solids." 178 A composition of matter is typically the category used to cover chemicals, which might not otherwise fall under one of the categories of $\S$ $101 .{ }^{179}$ However, the boundaries of what is and is not a composition of matter have not been extensively examined by the courts. In almost all cases, an inquiry into which category of invention a particular invention falls into is not necessary. The court in Nuijten acknowledged that such an inquiry is not usually necessary, noting that "[t]he question of whether a claim encompasses statutory subject matter should not focus on which of the four categories of subject matter a claim is directed to," although "the [claimed] subject matter must fall into at least one category of statutory subject matter." 180 The few cases that are available show that a composition of matter is not been limited to only covering particular molecules or phases of matter. The Supreme Court in Chakrabarty found that a genetically engineered bacterium was both a "manufacture" and a "composition of matter." 181 The entire bacterium was claimed in Chakrabarty, which would include a cell wall, DNA, plasmids, and other components of a bacterium. ${ }^{182}$ If the complex structure of a bacterium can be considered a composition of matter, then a physical medium such as glass carrying an electromagnetic signal can also be considered a composition of matter. The author of this Note has not found any case, other than those relating to signals per se, in which a claim directed to a physical embodiment has been explicitly found to not fall into the category of a composition of matter.

As discussed above, when a laser pulse travels through glass, such as in an optical fiber, the electric field from the laser signal applies a force to the electrons, moving them relative to the nuclei of the atoms of the glass. ${ }^{183}$ If the electrons were displaced in a particular pattern and then released, the displaced electrons would generate a signal reflecting the displacement pattern. ${ }^{184}$ In other words, applying the electromagnetic signal to the optical fiber transforms the fiber to a different configuration that did not exist prior to application of the signal. The configuration of such a transformed optical fiber fits well within the definition of a composition of matter used by the court in Nuijten: "[A]11 compositions of two or more substances and all composite articles, whether they be the results of chemical union, or of mechanical mixture, or whether they be

178. Chakrabarty, 447 U.S. at 308; In re Nuijten, 500 F.3d 1346, 1357 (Fed. Cir. 2007).

179. PIN/NIP, Inc. v. Platte Chem. Co. 304 F.3d 1235 (Fed. Cir. 2002) ("The term 'composition of matter' . . is the principal rubric under which chemical compounds are patentable (arguably, they can also be 'manufactures').”).

180. In re Nuijten, 500 F.3d at 1354 (quoting State St. Bank \& Tr. Co. v. Signature Fin. Grp., 149 F.3d 1368, 1375 n.9 (Fed. Cir. 1998)).

181. Chakrabarty, 447 U.S. at 308.

182. Id. at 305 n.1.

183. JACKSON, supra note 29.

184. Id. 
gases, fluids, powders or solids." ${ }^{185}$ Although a composition of matter typically refers to a molecule or chemical mixture, no binding precedent requires a court to find that an optical fiber with a certain signal imprinted on it could not be considered a composition of matter. Since most tangible articles clearly fall into the statutory category of an article of manufacture, there is little case law considering the question of the breadth of the "composition of matter" category.

\section{Claiming a Signal-carrying Medium}

Even if an applicant or patent-owner successfully convinced a court or the USPTO that a signal-carrying medium is patentable under certain circumstances as either an article of manufacture or a composition of matter, the applicant or patent owner must also convince the court or the USPTO that the claim does not cover a signal per se. As discussed above, the Patent Trial and Appeal Board at the USPTO held in a precedential decision that the broadest reasonable interpretation of a storage medium included a carrier wave. ${ }^{186}$ Additionally, the USPTO's position is that the broadest reasonable interpretation of a tangible medium includes signals per se. ${ }^{187}$ As a result, the USPTO would interpret a claim directed to a "tangible storage medium" to include a signal per se. One possible approach to overcome this interpretation of a computer-readable medium would be for an applicant to explicitly exclude carrier waves or other signals as possible embodiments of computer-readable media in the specification of the patent application. Another possible approach would be to alter the language of the claim to not include signals or carrier waves. For example, a claim directed to a computer-readable medium composed of matter could not be construed as an electromagnetic wave because, as Nuijten noted, an electromagnetic wave is not composed of matter. ${ }^{188}$ The claim at issue in Nuijten could be rewritten from "A signal with embedded supplemental data ..." to "A medium composed of matter carrying a signal with embedded supplemental data . ..."189 As another example, a claim directed to a computer-readable medium having mass could not be construed as an electromagnetic wave because electromagnetic waves do not have mass. ${ }^{190}$

\section{CONCLUSION}

The holding of Nuijten that a signal per se is not patentable has led to a void in patent protection for software patents. Foreign entities can sell and transmit patented software from outside the United States to end users. Since an inventor

185. In re Nuijten, 500 F.3d at 1357 (citing Chakrabarty, 447 U.S. at 308).

186. Ex parte Mewherter, No. 2012-007692, 107 U.S.P.Q.2d (BNA) 1857, 1860 (P.T.A.B. May 8, 2013) (precedential-in-part).

187. Office of Patent Legal Admin., supra note 53, at 17 ("Not acceptable to just add 'physical' or 'tangible' - Nuijten's ineligible signals were physical and tangible.”).

188. In re Nuijten, 500 F.3d at 1357.

189. Id. at 1351.

190. JACKSON, supra note 29. 
cannot patent a signal in transmission and cannot secure an exclusion order from the ITC, an inventor has no recourse against the foreign entity. As a result, the software patent-licensing industry - worth well over $\$ 100$ billion a year-is vulnerable to foreign entities facilitating infringement without remedy available to the inventor against the foreign entities. ${ }^{191}$ As is always the case in patent law, limiting protection of inventions stifles innovation, ultimately harming the end users. ${ }^{192}$ In this case, the end user is every person who uses software on a cell phone or other device. However, a careful analysis of Nuijten shows that one possible interpretation would require an article of manufacture to be tangible but not necessarily non-transitory. An optical fiber or electrical cable carrying a signal would meet the requirement of being a tangible article of manufacture and would thus be patentable subject matter, allowing a carefully crafted claim to cover a transmission medium carrying software. Even if courts interpret Nuijten as requiring an article of manufacture to be transitory, an optical fiber or electrical cable carrying a signal would still be patentable subject matter because it would fall into the category of a composition of matter. An inventor who receives such a patent could then argue to the ITC that transmission of patent software into the United States would infringe his patent and, therefore, the ITC should grant an exclusion order. Allowing patent holders to protect their inventions in this way would further the purpose of the patent system of incentivizing innovation to the benefit of the public.

191. Armstrong et al., supra note 3.

192. David Kline \& Bernard J. Cassidy, Are Software Patents Stifling Innovation?, IP WATCHDOG (Apr. 11, 2014), http://www.ipwatchdog.com/2014/04/11/are-software-patents-stiflinginnovation/id=48998/ [perma.cc/469U-ETV9]. 